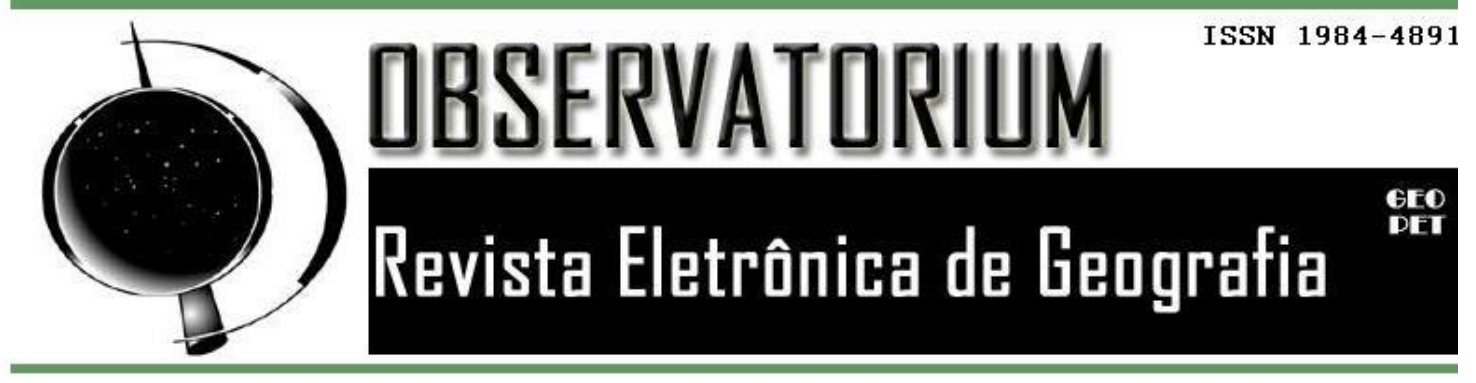

\title{
Uma análise da influência da infraestrutura escolar no processo de ensino-aprendizagem através do estágio supervisionado
}

Analysis of the influence of school infrastructure on the teaching-learning process through the supervised internship

\section{Beatriz Bicalho}

Pós-Graduanda pelo Programa de Pós-Graduação do Instituto de Geografia da Universidade Federal de Uberlândia

E-mail: beatrizbicalho94@gmail.com

\section{Resumo:}

O presente trabalho visa analisar, através das experiências vivenciadas na parte prática da disciplina de Estágio Supervisionado I, II e III nos anos de 2018 e 2019, abarcando turmas do ensino fundamental I, ensino fundamental II e ensino médio, como se dá o processo de ensino aprendizagem dos alunos da Escola Estadual Joaquim Saraiva, localizada na cidade de Uberlândia-MG, e qual a relação existente entre a infraestrutura da escola e esse processo.

Palavras-Chave: Experiência escolar. Realidade escolar. Infraestrutura escolar.

\begin{abstract}
:
The present work aims to analyze, through the experiences lived in the practical part of the Supervised Internship I, II and III discipline in the years 2018 and 2019, encompassing classes from elementary school I, elementary school II and high school, as it happens the process of teaching students learning at Escola Estadual Joaquim Saraiva, located in the city of Uberlândia-MG, and what is the relationship between the school infrastructure and this process.
\end{abstract}

Keywords:. School experience. School reality. School infrastructure. 


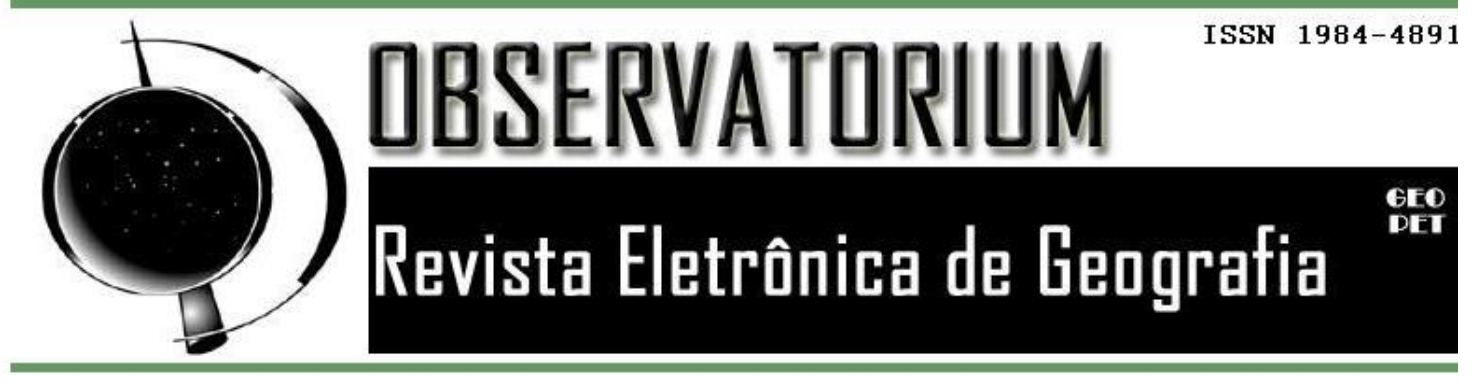

\section{Introdução:}

Entende-se a escola, a partir de uma concepção geral, como um espaço físico delimitado onde oferece uma estrutura necessária para o desenvolvimento de práticas educativas que visam oferecer ao aluno uma gama de conhecimentos para sua formação. Entende-se também que dentro dessa concepção geral existem os mais diversos tipos de escola e que os espaços constituídos pelas escolas públicas geralmente são mais degradados do que o de escolas particulares e a questão da infraestrutura escolar acaba se tornando um obstáculo no processo de ensino e aprendizagem no que cerne às condições necessárias para a realização do trabalho dos professores, realização de atividades extra salas de aula, para o aprendizado do aluno dentro da escola, entre outros.

Dessa maneira, o presente trabalho visa analisar, através das experiências vivenciadas na parte prática da disciplina de Estágio Supervisionado I, II e III nos anos de 2018 e 2019, abarcando turmas do ensino fundamental I, ensino fundamental II e ensino médio, como se dá o processo de ensino aprendizagem dos alunos da Escola Estada Joaquim Saraiva, localizada na cidade de Uberlândia-MG, e qual a relação existente entre a infraestrutura da escola e esse processo.

Compreende-se a importância do estágio para o estudante, futuro professor, no sentido de aprender e aperfeiçoar as técnicas e metodologias aprendidas dentro de sala de aula unificando o conhecimento prático ao teórico e abstraindo novas maneiras de se exercitar a profissão a partir do conhecimento prático ali adquirido, colaborando na integração do processo de formação do aluno a partir da compreensão de sua realizada escolar. Assim, a atividade de estágio fica reduzida à hora prática, ao "como fazer", às técnicas a serem empregadas em sala de aula, ao desenvolvimento de habilidades específicas do manejo da classe, ao preenchimento de fichas de observação, diagramas, fluxogramas (PIMENTA E LIMA, 2004. p.34). Assim posto, esse trabalho analisará primeiramente a estrutura geral da escola, seguida de uma análise da infraestrutura das salas de aula para então analisar as vivências escolares 


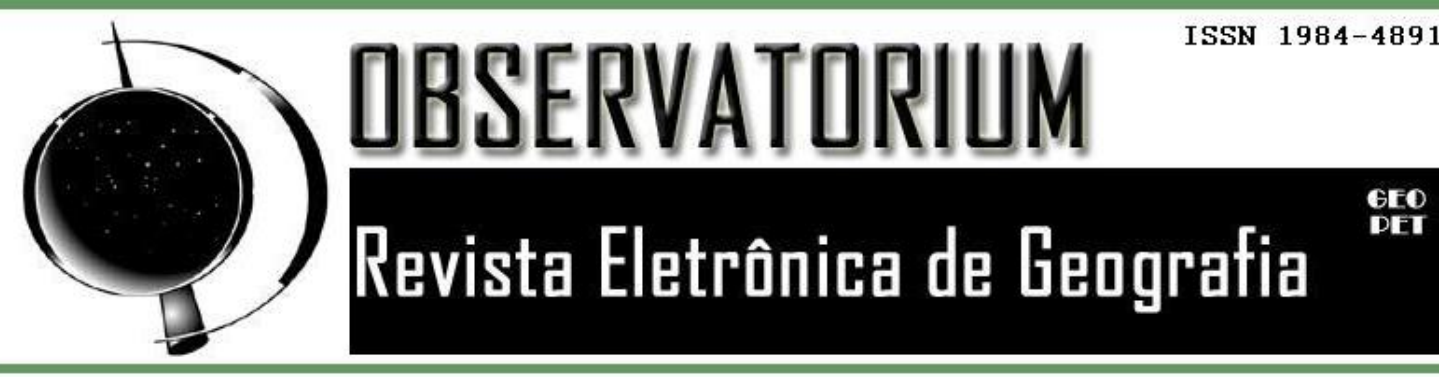

presenciadas nos períodos de prática do estágio e suas possíveis intervenções a partir da estrutura escolar analisada.

\section{Localização da escola e seu entorno}

A Escola Estadual Joaquim Saraiva encontra-se localizada no endereço Av. João XXIII, no 68, bairro Saraiva, na cidade de Uberlândia-MG. O bairro é considerado um bairro residencial, de moradores de classe média e classe média/alta, porém nas redondezas da escola compreendem também os bairros Santa Mônica e Lagoinha, o que justifica a percepção de uma grande variedade de classes sociais dos alunos na escola, ou seja, encontramos alunos com uma situação financeira aparentemente estável no mesmo local em que encontramos alunos que denunciam uma condição financeira instável. Sua localização se dá na esquina de duas vias de bastante movimento e o acesso de forma geral é fácil. Existem dois pontos de ônibus mais próximos, um na rua da escola, onde o A115, que faz a linha saraiva-terminal central, passa em frente a escola porém, seus horários são mais restritos e o tempo de espera por esse ônibus é maior, podendo chegar a até 30 (trinta) minutos de espera. A outra opção é a plataforma de ônibus da Av. João Naves de Ávila localizada dois quarteirões acima da escola, onde passa o T131 a cada cinco minutos.

A escola fica próxima à Universidade Federal de Uberlândia, à supermercados, farmácias e comércios em geral, tudo isso abrangendo aproximadamente uma distância de até cinco quarteirões da mesma. Observando a entrada dos alunos, percebe-se que a grande maioria destes se deslocam para a escola a pé ou de carro e que, vans e demais transportes pagos são pouco frequentes.

No entorno da escola têm se construído muitos prédios, o que não era muito frequente até alguns anos atrás, segundo um morador que abordei durante um breve passeio no quarteirão. Antigamente o muro da escola era baixo e ao lado deste existia um terreno baldio, onde os "malinhas do Lagoinha”, segundo relato deste morador, utilizavam para consumo de drogas, para pular o muro pra dentro da escola quando bem entendiam para jogarem bola na quadra. A 


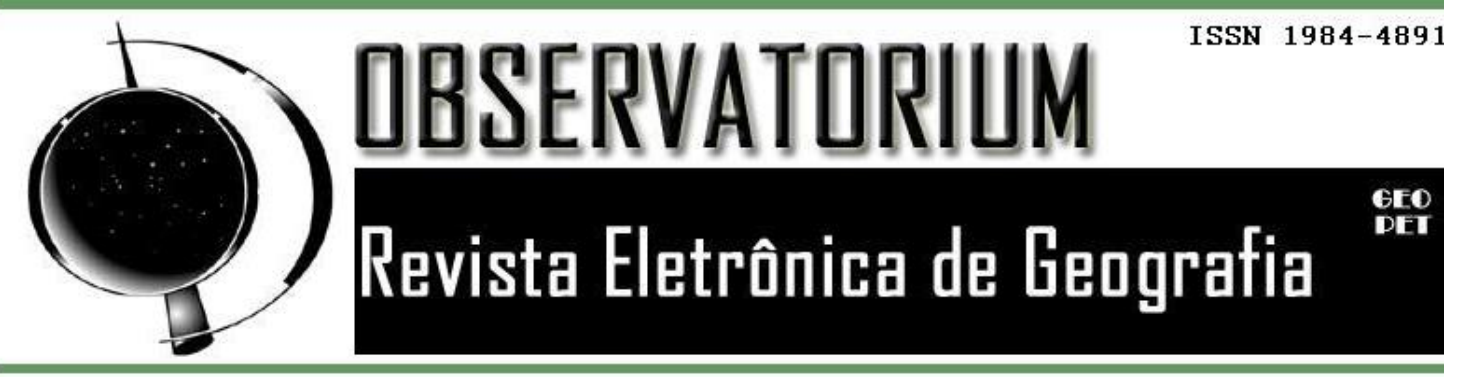

construção dos prédios modificou a paisagem do entorno da escola, porém, o terreno baldio e o muro agora se transformaram em um grande paredão impossível de ser pulado, mas um problema ainda vigente é a venda de drogas na portaria de cima da escola.
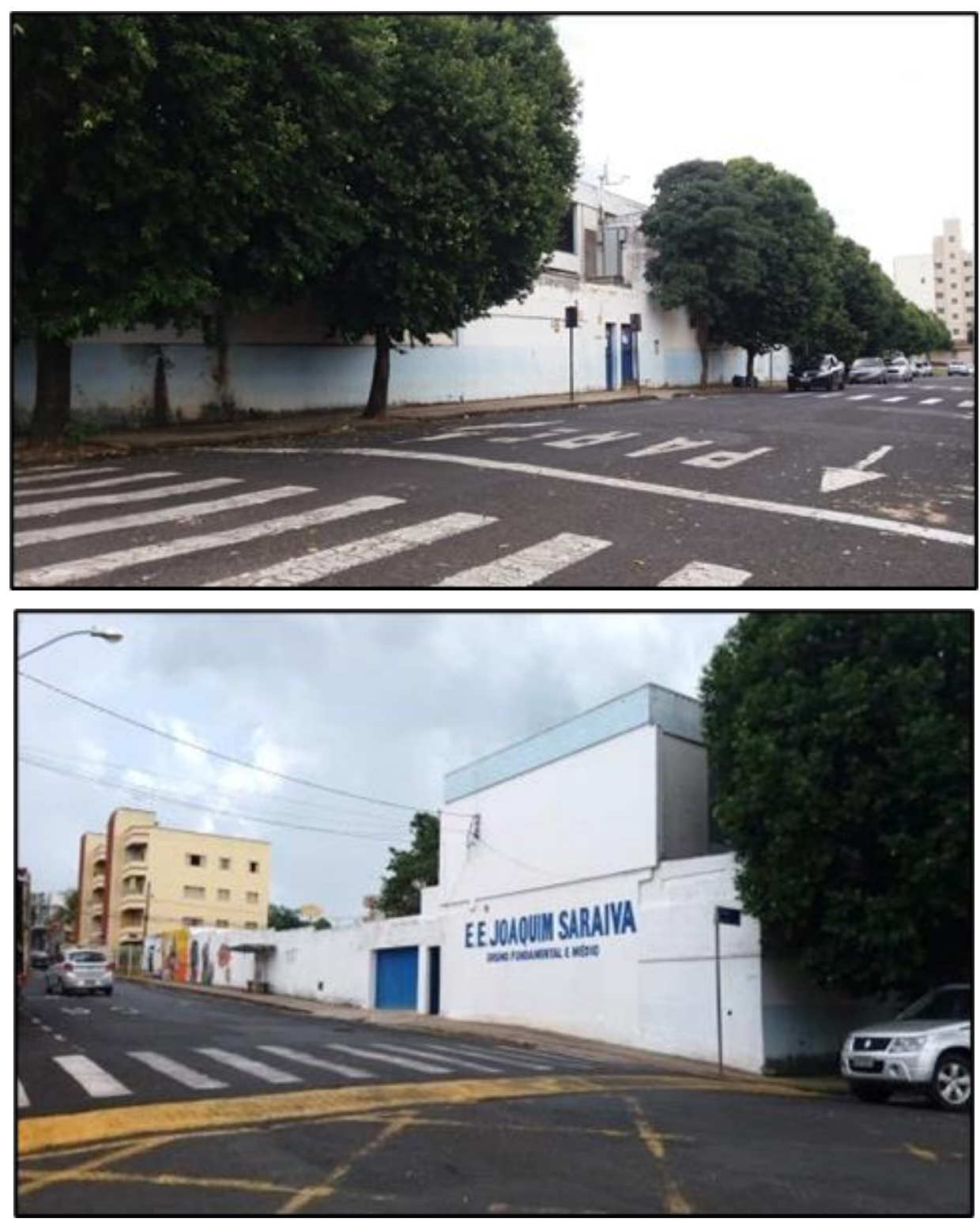

Imagem 01 : Vista da parte externa da escola. Fonte: a autora. 


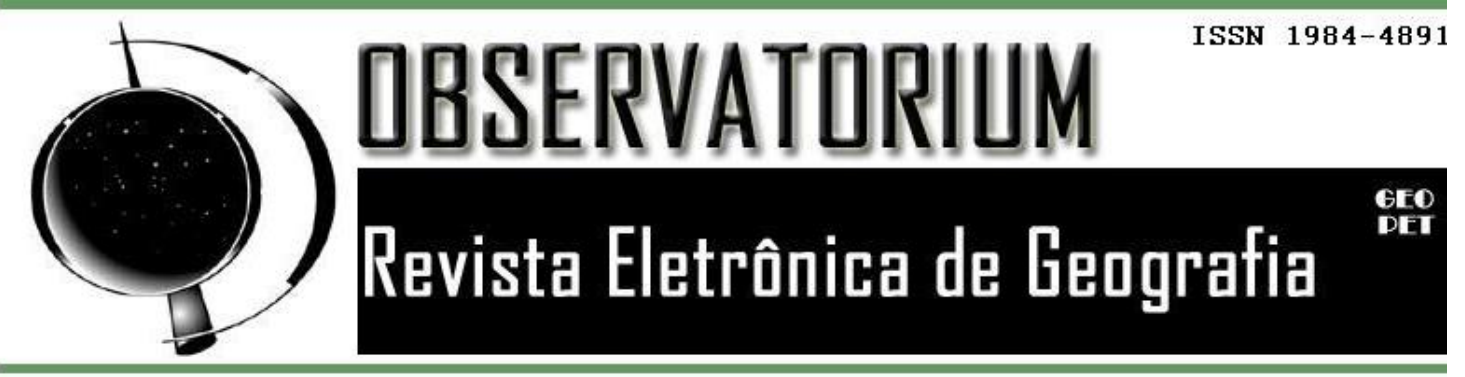

Infraestrutura da escola

O primeiro dia de atividades práticas no estágio foi destinado à observação da estrutura da escola como um todo, onde contemplou a estrutura das salas de aula, da biblioteca, da área externa, pátio, quadras, cantina, instalação de objetos de auxílio à acessibilidade, banheiros e coleta de lixo.

A Escola Estadual Joaquim Saraiva passa a impressão inicial de uma boa infraestrutura. A parte externa da escola, que corresponde ao pátio recreativo e às quadras, é bastante espaçosa e arborizada, possui uma quadra de futsal coberta com uma arquibancada, duas quadras menores com redes para jogos de vôlei, peteca e afins, um espaço aberto cercado por árvores e um espaço coberto onde estão localizadas mesas cumpridas em que os alunos jogam jogos de dama e afins, conforme pode ser ilustrado na imagem abaixo. Um ponto negativo é que existe um espaço de recreação atrás das quadras que é praticamente inutilizado. Apesar da dimensão desse espaço, a escola não investe em infraestrutura do mesmo para uso dos alunos.

O professor de Geografia informou que muitos professores, inclusive o mesmo, tem estratégias de passar exercícios em sala e levar os alunos para a arquibancada para que eles os façam e normalmente a biblioteca está sempre cheia ou fechada e a quadra tem alunos em horários de educação. Logo, a estruturação desse espaço inutilizado poderia ser uteis para que os alunos realizassem essas atividades fora de sala de aula.

A escola possui dois andares. O primeiro contempla salas de aula, parte recreativa, refeitório, banheiros, secretaria, biblioteca e sala dos professores. Já o segundo andar é anexado ao primeiro através de uma escadaria e de um elevador para pessoas portadoras de deficiência física. O segundo andar contempla um corredor grande que compreende um espaço apenas de salas de aula. 


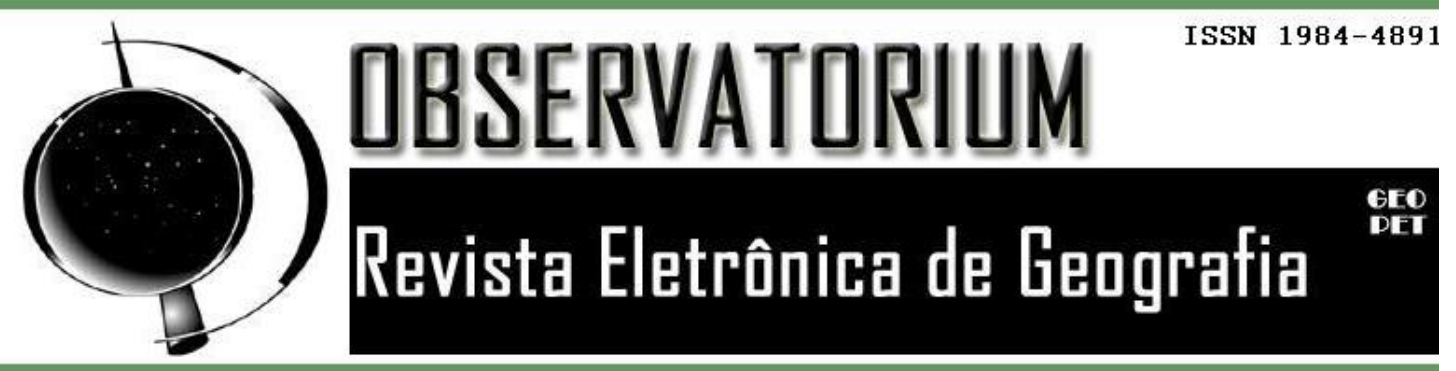

e bancos cumpridos, material de apoio didático para uso dos professores como mapas, cubos mágicos, relógios pedagógicos, entre outros, é utilizada como ambiente de estudos para as crianças mais atrasadas nas matérias, onde as auxiliares tomam leitura e tabuada das mesmas, e é utilizada também como espaço para realização de trabalhos pelos alunos, como por exemplo, confecção de materiais por parte dos alunos para a feira de ciências da escola, que ocorreu no dia 24 de novembro de 2018.

A bibliotecária possui um bom relacionamento com os alunos que ali frequentam e que está também cumpre o papel de professora substituta quando alguma outra professora falta. Um fato que chamou a atenção foi que a bibliotecária empresta livros para os alunos que esqueceram os seus ocasionalmente, como foi o caso que presenciei de uma estudante que esqueceu o livro de artes em casa e pôde pegar por um dia na biblioteca para não ficar atrasada em sala. Além desse caso específico do empréstimo de material didático, outros itens são emprestados para auxiliar nas aulas, como tesouras, colas, entre outros. Os alunos assinam um caderno com a data do empréstimo e se comprometem a devolver após o término do uso.
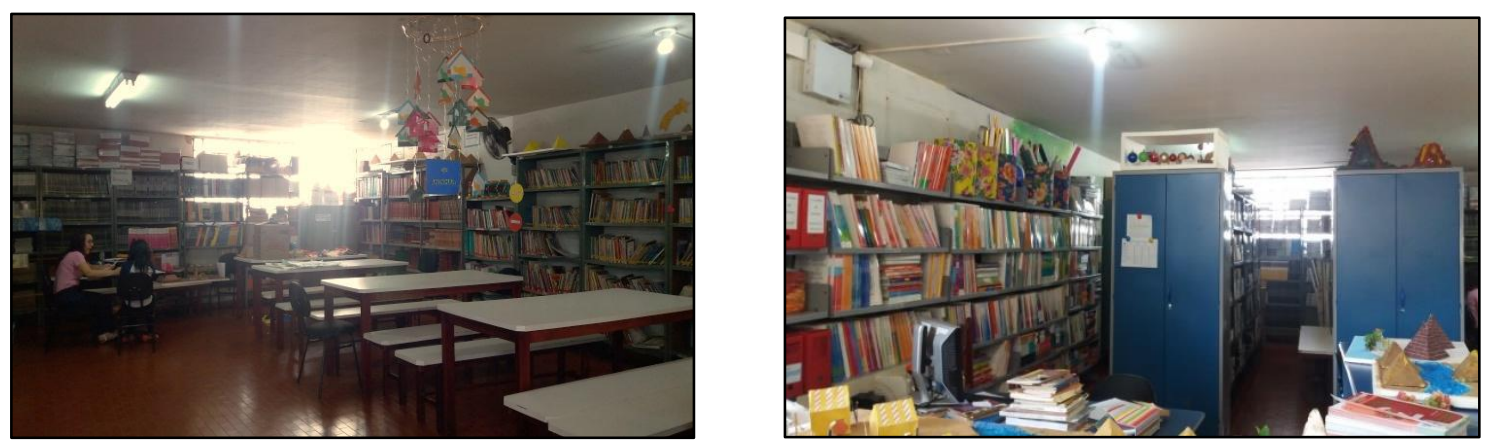

Imagem 3: A estrutura da biblioteca da escola. Fonte: a autora 


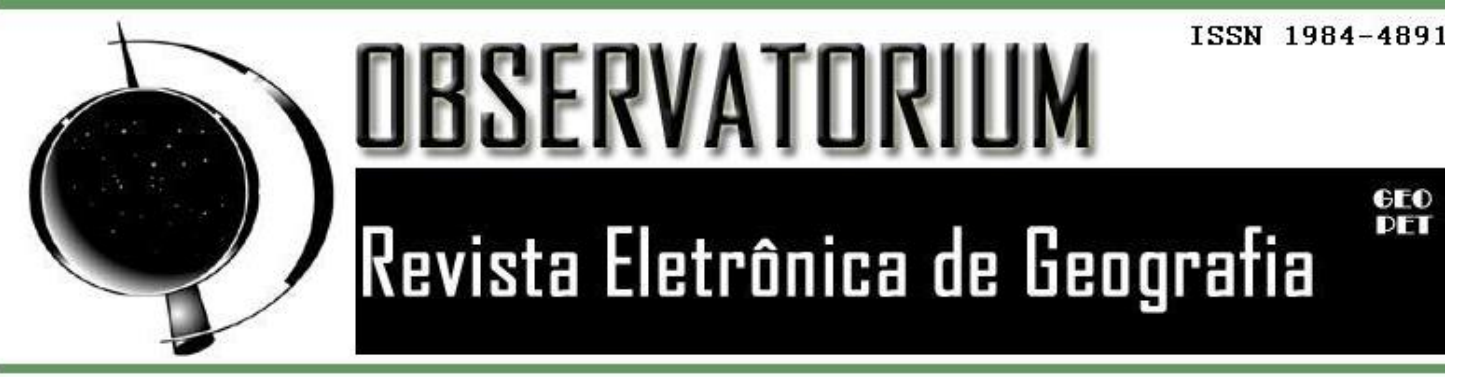

O refeitório

A primeira observação ao ver a dimensão do espaço destinado ao refeitório é de que o mesmo não comporta todos os alunos da escola, como pode ser observado na imagem 4. Logo, pensei nas estratégias que a escola propôs para resolver este problema de falta de espaço e as alternativas pensadas foram a seguintes: existem mesas dispostas na área externa coberta de recreação e existem dois recreios; o primeiro para crianças do $1^{\circ}$ ao $5^{\circ}$ ano, e o segundo para os estudantes de $6^{\circ}$ ao $8^{\circ}$ ano. O lanche é servido pelas cantineiras, e as crianças que desejam repetir, devem entrar ao final da fila e respeitar a ordem dos que ainda não comeram. Já o cardápio é variado em todos os dias da semana.

Uma observação importante é que a impressão que eu tive era de que a grande maioria dos alunos da escola, ao menos no período da tarde em que vivenciei tais experiências, não comem o lanche da escola, e muitos levam salgadinhos e bolachas de casa para comer no recreio. Outra observação é que a escola avisa aos alunos com um dia de antecedência que fará cachorro quente com guaraná e venderá no recreio por cinco reais, então os alunos interessados levam o dinheiro no dia posterior e compram no recreio. A supervisora informou que esta é uma forma da escola ganhar dinheiro por fora, já que a verba enviada pelo Estado nem sempre é suficiente. 

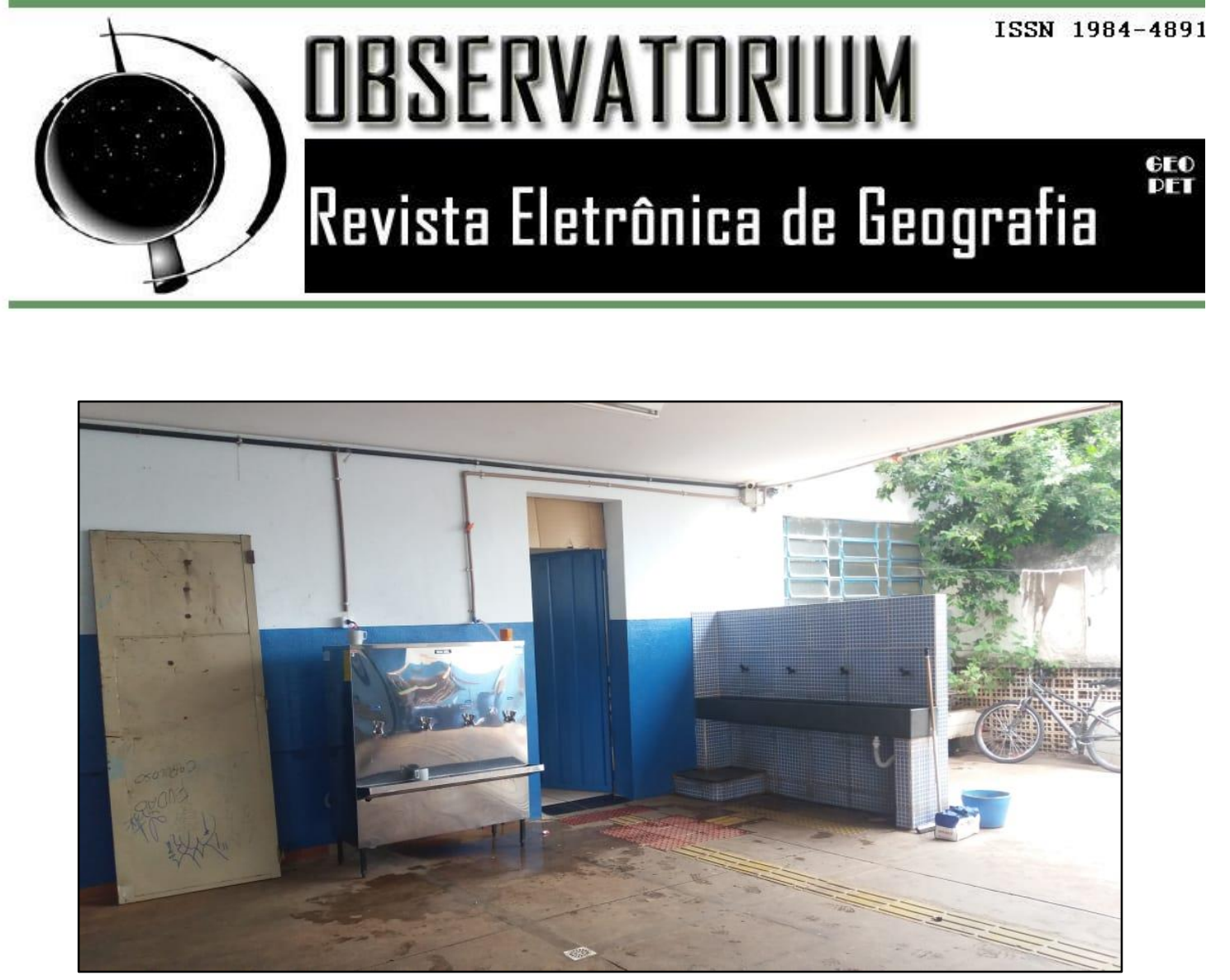

Imagem 05: Bebedouros novo (esq.) e antigo (dir.). Fonte: a autora

Já a estrutura dos banheiros, em aspectos gerais, pode ser considerada como razoável. Ao menos no banheiro feminino, do qual visitei, todos os cinco vasos sanitários e torneiras funcionavam, porém não havia papel higiênico e as paredes eram pichadas com marcas de batom vermelho, espelho quebrado e canetas permanentes. Pode-se observar a estrutura do mesmo de acordo com as imagens abaixo.

Imagem 6. Estrutura do banheiro feminino. Fonte: a autora
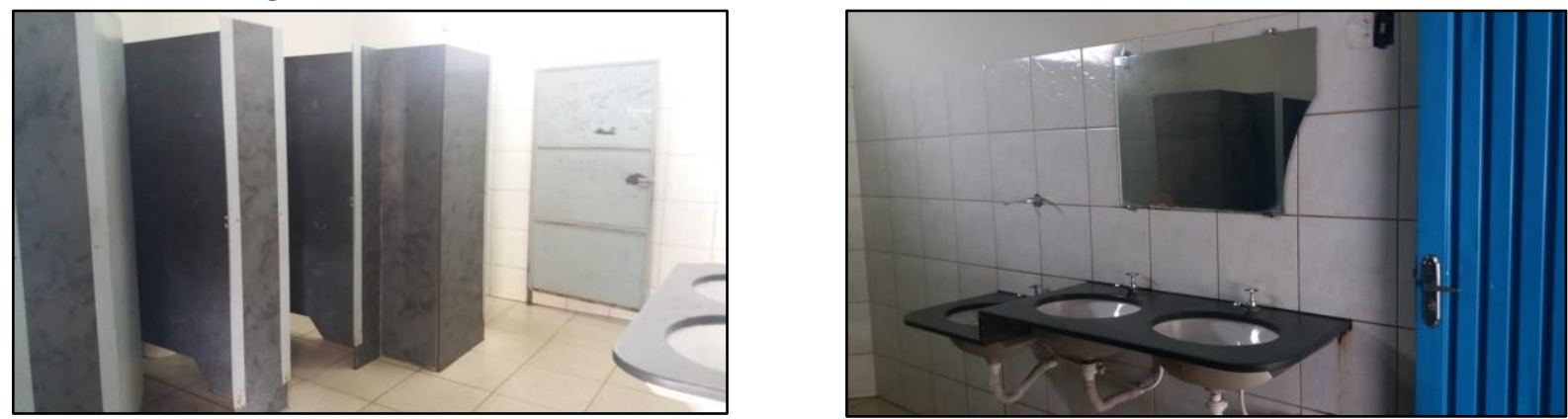


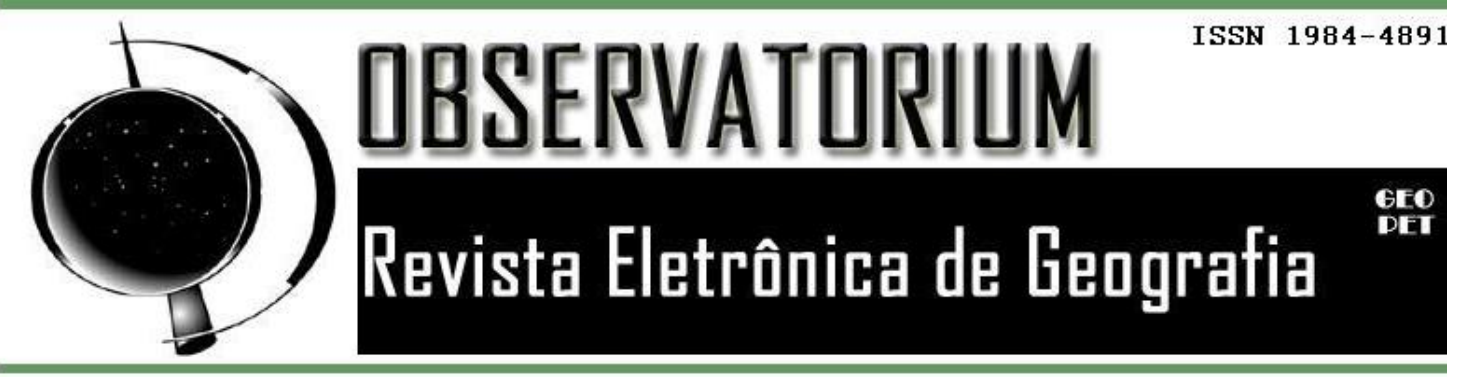

\section{A sala de aula}

A respeito da estrutura das salas de aula, tomei a liberdade de dividilas em dois tipos: as do primeiro andar que compreendem salas mais escuras, das quais tive a impressão que foram adaptadas à situação de sala de aula, das quais acompanhei uma das turmas. As do segundo andar, que são mais arejadas, possuem janelas maiores, portanto, mais iluminação natural. Todas as janelas das salas do segundo andar possuem grades devido à questões de segurança dos alunos, e todas as salas de aula da escola possuem um quadro branco. O espaço de cada uma delas comporta aproximadamente 35 crianças com tranquilidade, porém, nas turmas de $6^{\circ}$ ao $9^{\circ}$ ano principalmente, o número de alunos por salas era maior que a capacidade de alunos por sala.

Das salas em que realizei o estágio são quase todas no segundo andar, com exceção apenas de uma. O número de alunos por sala, conforme informado acima, é notavelmente maior do que a capacidade da sala, ao menos na maioria delas. Na lista de chamada nota-se que muitos alunos, por motivos não conhecidos, saíram da escola.

Todas as salas possuem quadro branco, do qual é utilizado pelos professores para passar as matérias aos alunos. As paredes são pintadas da cor bege e a iluminação é razoavelmente boa para o ambiente. Também possui dois ventiladores, um na frente e um ao fundo da sala, mesas e cadeiras para os alunos e professores e um armário. Diferentemente das turmas do ensino fundamental I, as salas correspondentes ao ensino fundamental II e ensino médio, não possuem elementos comunicativos nas paredes. A estrutura das salas pode ser ilustrada de acordo com a imagem abaixo. 

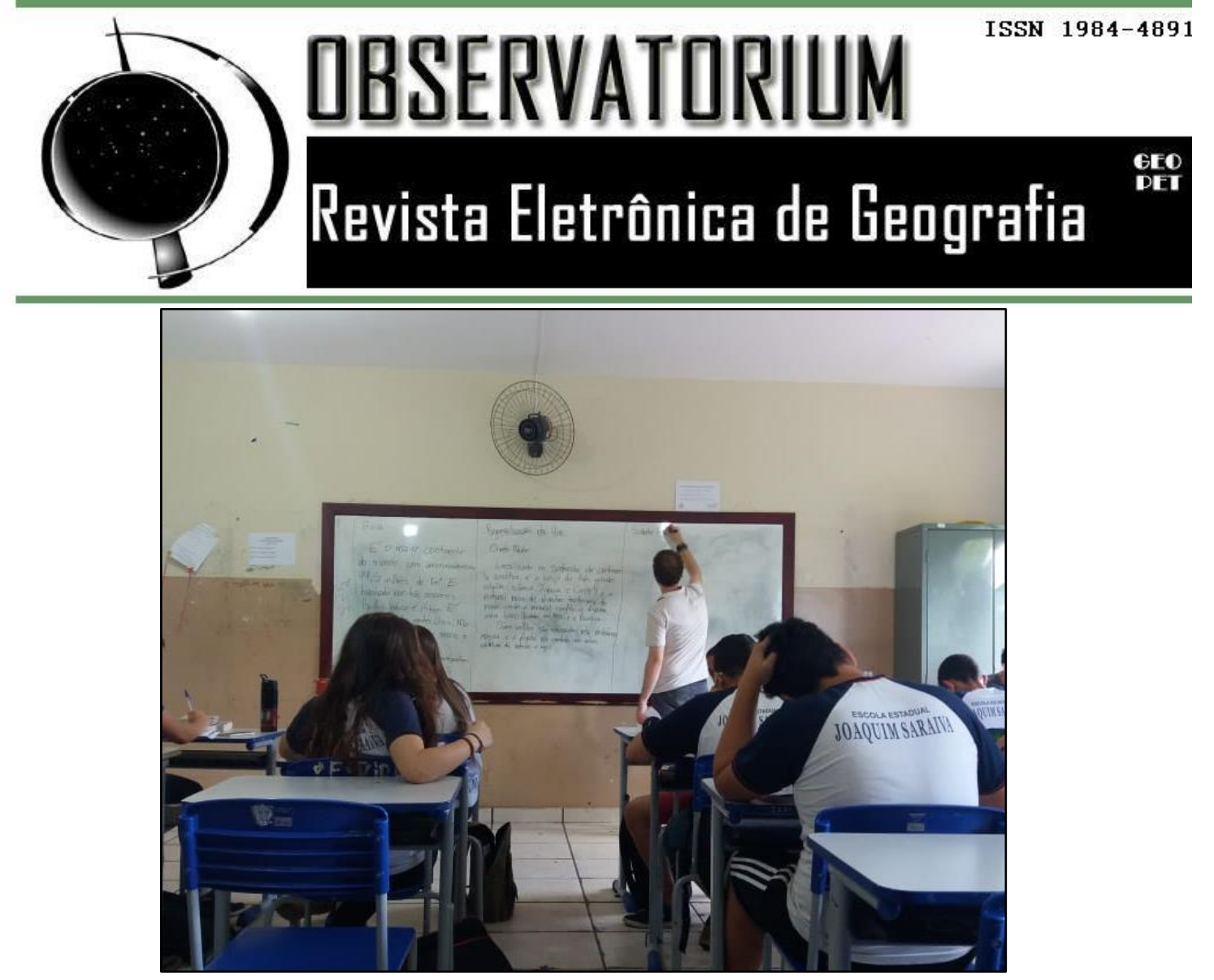

Imagem 07: Estrutura da sala de aula. Fonte: a autora

\section{A influência da estrutura da escola no processo de ensino aprendizagem}

Conforme aponta Satyro e Soares (2008, p.09), insumos escolares são entendidos como infraestrutura de todo tipo: número médio de alunos por turma, número de horas/aula, docentes com formação superior, construção e melhoria das dependências da escola, existência de biblioteca ou sala de leitura e outros aspectos positivos. Infraestrutura é, nesse caso, tudo aquilo que o dinheiro pode comprar que, nesse caso, deve ser fornecido pelo Estado.

Ao analisar o quadro da Escola Estadual Joaquim Saraiva pode-se perceber que a realidade da qual é inserida não difere muito da realidade de grande parte das escolas públicas espalhadas por todo o Brasil.

O primeiro fator importante a ser apontado para tal discussão é a superlotação das salas de aula, que se torna uma influência direta no processo de ensino-aprendizagem e na absorção do conhecimento por parte dos alunos na medida em que a superlotação facilita a desordem dentro de sala e acaba por sobrecarregar o professor, que tenta ao mesmo tempo em que dá a aula, conter a indisciplina e controlar a desconcentração dos alunos. Outro fator que podemos 


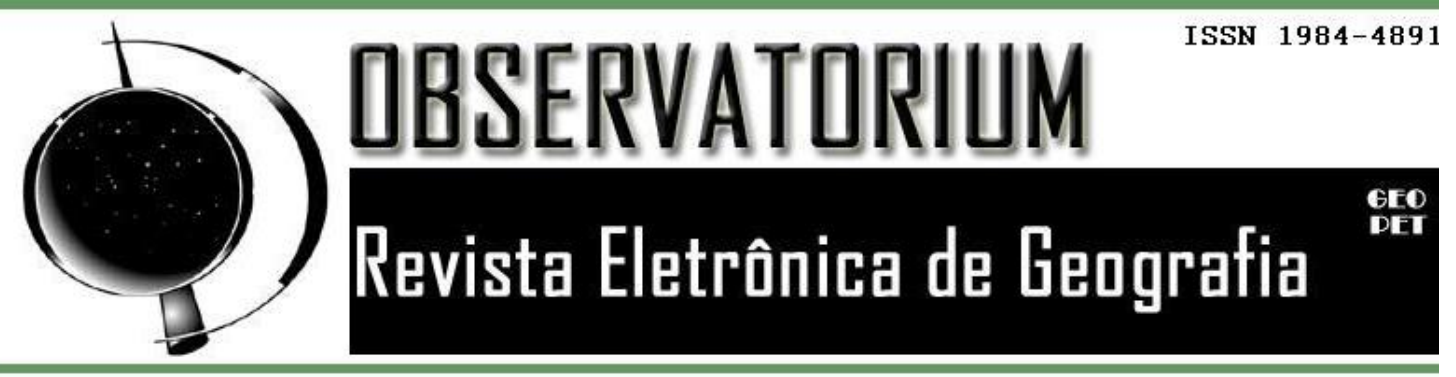

ressaltar é a adaptação de espaços da escola como sala de aula, isso ocorre porque exige uma demanda de alunos para a escola, porém, a verba recebida anualmente não é proporcional ao aumento dessa demanda logo, a escola acaba por ter que investir na adaptação de espaços para sala de aula, como é o caso da sala de vídeo que também serve como sala de aula reserva, nesse remanejamento muitas das vezes não é pensada a questão da ventilação ou da iluminação, ou se o tamanho da sala de aula é proporcional à quantidade de alunos.

Dois novos espaços da escola foram adaptados para se tornarem sala de aula, dos quais anteriormente eram utilizados como depósitos, dessa forma, essas novas salas de aula possuem uma infraestrutura precária comparada às demais salas da escola, com pouca iluminação, pouca ventilação e totalmente afastada das demais salas de aula. O espaço de recreação também pode ser analisado através de uma perspectiva crítica no sentido de ser amplo e os profissionais da escola não terem controle sobre os alunos no horário de recreação e, para além disso, o espaço poderia ser melhor aproveitado de forma a proporcionar para os docentes trabalhar com os estudantes fora de sala de aula de uma forma mais dinâmica e criativa.

\section{CONCLUSÃo}

Pode-se concluir a partir dos apontamentos acima realizados que o estágio supervisionado oferece ao futuro professor uma excelente fonte de reflexões e problematizações acerca do tema e que, muitas das vezes, o processo de ensino-aprendizagem não é eficiente como a teoria aponta por conta das dificuldades inseridas nesse processo, sejam elas a falha estrutura escolar ou até mesmo as precárias condições de pagamento para o professor que o leva a procurar emprego em várias escolas e fazer até três turnos em um mesmo dia.

Dessa forma, dadas as condições, o professor não pode ser o agente responsável pela melhora da estrutura escolar. Mesmo assim, há muitos casos em que o próprio professor dispõe de esforços para conseguir trabalhar com os 


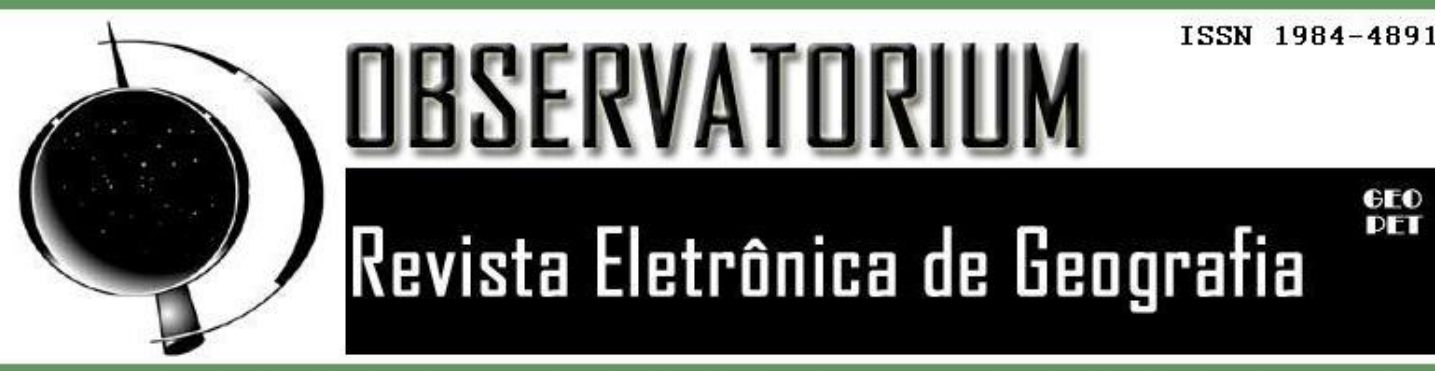

alunos de maneira criativa e eficiente, muitas vezes retirando dinheiro do próprio bolso para possibilitar que os alunos tenham o material didático suficiente.

Percebe-se que a estrutura escolar, principalmente no que cerne a realidade das escolas públicas, necessita de uma mudança e investimentos que possibilitem melhorar o ambiente escolar e, consequentemente, o processo de ensino-aprendizagem.

\section{REFERÊNCIAS}

PIMENTA, Selma Garrido; LIMA, Maria Socorro Lucena. Estágio e Docência. São Paulo: Cortez, 2004. PILETTI, Claudino. Didática geral. São Paulo: Ática, 2004.

SATYRO, Natália; SOARES, Sergei. A infraestrutura das escolas brasileiras de ensino fundamental: um estudo com base nos censos escolares de 1997 a 2005. Brasília: IPEA, 2007. 